\title{
The Most Frequent Metacognitive Strategies Used in Reading Comprehension among ESP Learners
}

\author{
Hooshang Khoshsima \\ Faculty of Management and Humanities, Chabahar Maritime University, Chabahar, Iran \\ E-mail: Khoshsima2002@yahoo.com \\ Elham Amiri Samani (Corresponding author) \\ Faculty of Management and Humanities, Chabahar Maritime University, Chabahar, Iran \\ E-mail: amirisamanielham@gmail.com
}

Doi:10.7575/aiac.alls.v.6n.1p.180

URL: http://dx.doi.org/10.7575/aiac.alls.v.6n.1p.180
Received: 30/09/2014

Accepted: 15/12/2014

\begin{abstract}
Reading strategies are plans for solving problems encountered during reading while learners are deeply engage with the text. So, comprehension is not a simple decoding of symbols, but a complex multidimensional process in which the leaner draws on previous schemata applying strategies consciously. In fact, metacognitive strategies are accessible versatile vehicles if the readers are aware and cognizant of their applications. This paper studied the most frequent used strategies by Iranian ESP students. Fifty six students completed 30-item questionnaire of MARSI (2002). It included three strategy categories: Problem Solving strategies (PROB), Global Reading strategies (GLOB), and Support strategies (SUP). Results indicated that students at the highest level perceived PROB strategies up to 58.93\%, SUP strategies up to $32.14 \%$, and GLOB strategies up to $30.37 \%$. Ranking the individual strategies represented that the highest used strategies are strategy 8 (overall mean= 3.51), strategy 20 (overall mean=3.52) and strategy 11 (overall mean=3.77).
\end{abstract}

Keywords: ESP, Metacognitive strategies, Problem Solving strategies, Global Reading strategies, Support strategies

\section{Introduction}

Reading is the bases of literacy, and absorbing meaning is the final goal of it. Hoover and Gough (1990) defines reading as the "product of decoding and comprehension" (Flynn \& Stainthorp, 2006, p. 42). Reading development does not happen in one stage; reader shows weaknesses at the early stages and makes use of strategies to compensate for his/her shortcomings and to make the best use of his /her knowledge. Maybe, strategies are abstract part of the reading and become visible only in practice. How to know that we know them? How to know how much of our knowledge of them is in common with others? Nunan (2006) states strategies are "mental" and "communicative procedures" employed by the learners to learn and use language appropriately. Decadesago and Dolores Durkin (1978-1979) in McLaughlin (2010) define reading as "comprehension" and teaching should focus on the strategies reader applies to make sense of the text. Competence is different from comprehension. Competence as "non-observable ability" is a kind of knowledge while comprehension is a kind of performance, a "willful act" (Brown, 2006, pp.35-39). So, Reading is not just verbalizing the printed words. Clustering the words is purposeful and reading is to decode the meaning potential of the text.

Reading is a part of language learning and language a social matter, so language and culture are densely interwoven. Besides, culture is a multi-dimensional and complex concept, it includes the "professional, personal, national and organizational cultures; language reflects the culture and culture can shape language" (Dudley-Evans \& John, 1998, p. 66). Culture-bounded strategies which are suitable to the target genre could be informative in the processes of syllabus designing, material writing, methodology application, and explicit strategy training. Mahdavi (2012) in his study on strategy training concluded metacognitive strategy training will have positive effect on the EFL Reading and vocabulary development in an "Input poor" Environment. Investigators have found a "statistical" link between students' L2 learning strategies and their underlying learning styles which are idiosyncratic and culture-oriented values (Ehrman \& Oxford, 1990; Ely, 1989, cited in Richards et.al, 2002) and so are strategy selections. A handy list of ranked strategies would be suggestive for the teachers to start explicit instruction from the top of the ranking to the bottom.

This study focuses on finding the most frequent strategies used by the Iranian ESP learners. The results have implementations for learners, teachers to instruct strategies which are culturally, contextually and psychologically more applicable. The course and syllabus designers, material writers and whoever is interested in teaching and learning ESP reading comprehension also benefit the results. 


\section{Research Questions}

Regarding the importance of underlying processes in reading comprehension, the study is to cast some light on the following questions:

Q1. Are the learners aware of the conscious strategy use?

Q2. What are the most frequently used and practical strategies among Iranian ESP learners?

\section{Literature Review}

Text is a vehicle of information and the importance of reading lies on the application of text information (DudleyEvans \& St John, 1998). Good readers apply comprehension strategies to facilitate the meaning construction (McLaughlin, 2010); they know what strategy to use where and when. Reading comprehension (RC) is a "social constructivist process". Reading is a linguistic behavior and the key to unlock some aspects of meaning is applying linguistic and strategic knowledge. Reader is deeply engaged using thinking skills, prior knowledge, and experiences; it has a dynamic nature (Lindsay \& Knight, 2010; Brown, 2006; Nunan, 2006; Dudley-Evans \& St John, 1998). In fact, in skill-oriented ESP classrooms like Iran that the focus of instruction is on one or some of the macro skills especially reading, and strategy application is crucial for text interpretation.

\subsection{Theoretical Framework}

Reading is an interactive process interpretation of text involving simultaneous "coordination of attention, perception and memory" (Clarke, 1980; Kern, 1989; Phillips, 1984, as cited in Haley \& Austin, 2004, p. 151). As Dudly-Evans \& St. John (1998) puts it, there exists two stages in reading comprehension (RC): 1- to process the text language, 2- to relate the understanding of the text to the previous schemata in both stages strategies come to act in order to expand the old information or to generate new one. Reid (1998, as cited in Wearmouth; Soler \&Reid, 2003; Nunan, 2006) notes there are two principle models of reading: the 'bottom-up' which reader starts from the written components of the text and gradually extracts the meaning; the second type is 'top-down' modal in which the reader takes an analytic view encountering the text and puts priority on getting the meaning. But, in practice it is not possible to absolutely draw a boundary between these two because reader is actively involved and unconsciously or consciously hangs together approaches. Wearmouth et.al (2003) and Nunan (2006) believe in the "interactive approach".

Regarding the learners' strategy use abilities, in one view, they are divided into effective learners and less successful learners. The former uses strategies frequently and appropriately, the latter fails to use strategies effectively; they may be as frequent strategy users as successful readers but their difference comes from the appropriate application. If one uses strategies in fragmented manner, its outcome will be drawing back rather than pushing forwards (Vann\& Abraham, 1989, cited in Richards and Renandia, 2002). They continue that less effective learners apply (metacognitive) strategies in a "random, even desperate manner" without integrating attention to the target task. Metacognitive strategies are "knowing about one's knowing" (Williams \& Burden, 1997, p. 148), they have "executive" function which involves planning, thinking about the learning process, monitoring of one's production, comprehension and evaluation after the acting is completed (Brown, 2006, p.134). Strategies are 'purposeful and goal-oriented'. Effective learning is not a matter of high IQ, but the learner's ability to respond appropriately to a learning situation leads him/her to an effective learning (Williams \& Burden, 2002).

Strategy awareness is also called conscious use of strategy or metacognitive strategy since students use them for planning, monitoring, evaluating and thinking about the learning process (Brown, 2006, p.134). Various specialists proposed categories of strategies each one building on and extending the previous ones. Among the most comprehensive ones is Oxford's. He added affective and social categories to the cognitive and metacognitive strategies suggested in the past. Where is the place of local variation in the learning society? Undoubtedly cross-sectional studies will show the social effects on the type and scope of strategy use. This system of categorization divides strategies into two main classes, direct and indirect, which are further subdivided into six groups. Direct strategies include: memory, cognitive strategies and compensation strategies, while indirect strategies include: metacognitive strategies, affective strategies and social strategies (William \& Burden, 2002).

Learners need to interpret a text in order to understand and communicate the message. To do this, they have to develop reading skills and strategies (Lindasay\& Knight, 2010). In ESP, genres carry communicative purposes which are reflected in very structure and grammatical form of text (Nunan, 2006). How much learners need proficiency in reading is closely related with the target use and the situation in which ESP is learned. Dudley-Evans \& St John (1998) poses four different situations for ESP teaching: an English speaking context; English as a second language context; a context in which certain subjects are taught in English; a context in which all the subject maters are taught in English (In Iran, ESP is taught in the fourth situations). Since, students' English proficiency up to tertiary level generally is in the area of general English, learners may not suitably be prepared for academic studies. Thus, it would be ESP teacher's duty to make students familiar with strategies and help them become conscious strategy users.

\subsection{Related Studies}

In the study of strategies, the idea of awareness has been the focus of studies. Many studies extended and reported valuable issues in this or other related areas. Among them we can mention the following studies.

Stok (2012) carried out a study on the building main idea comprehension among FL university students. 40 students of Faculated de Ciencias Socials participated in the study. Results showed that the major causes of difficulties in Main Idea Building (MIB) are the lack of interaction between high proficiency use and high strategy use. It is important to 
develop strategies for getting power in distinguishing main idea from secondary ideas; realizing processes implied in MIB and self-evaluating of one's own production.

In the study on ESP university students' reading strategy awareness, Martinez (2008) took 157 non-native English speaking Spanish students. Results showed that learners highly used problem solving and global reading strategies. He also claimed gender differences lead to different strategy use. Not only strategy awareness but also individual characteristics are determinant of strategy application.

Along the same lines Jafari \& Shokrpour (2012) investigated the reading strategies of Iranian ESP students while reading authentic expository texts. Eighty one students at Shiraz university of Medical Sciences participated in the study. They concluded that students used strategies differently according to their academic major.

Besides, Abdul Aziz (2011) examined on the Malaysia's university students. The results showed lower level of strategy awareness and strategy use would be related to low ability readers. Tabatabaie\& Assar (2011) applied SORS questionnaire on 90 intermediate ESP learners. Subjects claimed preference for problem solving strategies regardless of their academic field of study.

\section{Method}

\subsection{Participants}

The study is carried out among 56 university students majoring in Marketing Management and Information Technology (IT). All with Persian speaking background; and most of their courses are taught in Persian. At the time of study they were coping with their ESP courses. 26 were majoring in Chabahar Maritime University and 30 were Shahrekord Elmi-Karbordi students. They completed the Farsi-backed translated version of MARSI (2002) questionnaire in about fifteen minutes. The participants' age ranged from 19 to 27 years old. Gender distribution was similar to following: 24 female and 32 male. Participants' general English mark ranged from 12 to 20.

\subsection{Procedure}

The Farsi-backed version of MARSI questionnaire (2002) was provided for the study purpose. It included 30 strategies, questions about their course of study, gender, age, and general English mark. At first, the examiners were given some guidelines about how to complete, and assured their information will be kept confidentially. There were no right or wrong answer by its own and they should check one option for each statement. Then, to validate the answers, participants answered in one session and in the same place, the researcher put time limit of fifteen minutes and gave no chance of reviewing answers. The date was computed using the Statistical Package for Social Sciences (Spss) version 18.0 .

\section{Results and Data Analysis}

\subsection{Rank Ordering of Overall Mean Scores}

A qualitative comparison design was employed in this study. After gathering data through questionnaire, the first step the researcher took was to use descriptive statistics entry of Spss $18^{\text {th }}$. Considering the "key to average" provided in MARSI inventory (2002), and comparing the overall mean scores of the three main categories the results show that none of them is used at the lower level.

Individual scores from the questionnaires that were grouped together according to their sub scale categories (that is, GLOB, PROB, and SUP) were entered to descriptive entry of Spss $18^{\text {th }}$. So there were a mean score for each subcategory in each questionnaire. As the result, there were 56 mean scores for each sub-category $(\mathrm{N}=56)$. Then the overall mean for each sub-category calculated. The issues of statistics report overall mean of GLOB $=3.14$ (Medium level); overall mean of PROB $=3.40$ (Medium level, next to High); and overall mean of SUP $=3.06$ (Medium level).

Table 1. Rank ordering of overall mean scores and descriptive statistics of individual strategies $(\mathrm{N}=56)$

\begin{tabular}{|c|c|c|c|c|}
\hline 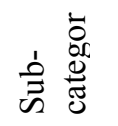 & Strategy & $\stackrel{\Xi}{\Xi}$ & & 卷 \\
\hline \multicolumn{5}{|c|}{ Medium use } \\
\hline GLOB & $\begin{array}{l}\text { 22- I use typographical aids like bold face and italics to identify key } \\
\text { information. }\end{array}$ & 2.60 & 1 & \\
\hline GLOB & 7- I think about whether the content of the text fits my reading purpose. & 2.66 & 1 & 2 \\
\hline SUP & 6- I summarize what I read to reflect on important information in the text. & 2.73 & & \\
\hline SUP & 28- I ask myself questions I like to have answered in the text. & 2.73 & 2 & 25 \\
\hline GLOB & 29- I check to see if my guesses about the text are right or wrong. & 2.77 & 1 & 5 \\
\hline GLOB & 14- I decide what to read closely and what to ignore. & 2.85 & 1 & 6 \\
\hline GLOB & 26- I try to guess what the material is about when I read. & 2.98 & 1 & 7 \\
\hline SUP & 2- I take notes while reading to help me understand what I read. & 2.99 & 1 & 8 \\
\hline SUP & 24- I go back and forth in the text to find relationships among ideas in it. & 3.12 & 1 & 9 \\
\hline GLOB & 10- I skim the text first by noting characteristics like length and organization. & 3.19 & 1 & 10 \\
\hline
\end{tabular}




\begin{tabular}{|c|c|c|c|c|}
\hline PROB & 13- I adjust my reading speed according to what I'm reading. & 3.20 & 1 & 11 \\
\hline PROB & 18- I stop from time to time and think about what I'm reading. & 3.22 & 1 & 12 \\
\hline GLOB & 1- I have a purpose in mind when I read. & 3.23 & 1 & 13 \\
\hline GLOB & 19- I use context clues to help me better understand what I'm reading. & 3.26 & & \\
\hline GLOB & 25- I check my understanding when I come across conflicting information. & 3.26 & 2 & 14.5 \\
\hline PROB & 16- When text becomes difficult, I pay closer attention to what I'm reading. & 3.30 & & \\
\hline PROB & 21- I try to picture or visualize information to help remember what I read. & 3.30 & & \\
\hline GLOB & 23- I critically analyze and evaluate the information presented in the text. & 3.32 & 1 & $\begin{array}{c}16.5 \\
18\end{array}$ \\
\hline PROB & 30- I try to guess the meaning of unknown words or phrases. & 3.33 & 1 & 19 \\
\hline GLOB & 3- I think about what I know to help me understand what I read. & 3.35 & & \\
\hline SUP & $\begin{array}{l}\text { 15- I use reference materials such as dictionaries to help me understand what I } \\
\text { read. }\end{array}$ & 3.35 & 2 & 20.5 \\
\hline SUP & 5- When text becomes difficult, I read aloud to help me understand what I read. & 3.39 & 1 & 22 \\
\hline GLOB & 4- I preview the text to see what it's about before reading it. & 3.40 & 2 & \\
\hline SUP & 9- I discuss what I read with others to check my understanding. & 3.40 & & 23.5 \\
\hline GLOB & 17- I use tables, figures, and pictures in text to increase my understanding. & 3.44 & 1 & 25 \\
\hline PROB & 27- When text becomes difficult, I re-read to increase my understanding. & 3.48 & & \\
\hline SUP & 12- I underline or circle information in the text to help me remember it. & 3.48 & 2 & 26.5 \\
\hline PROB & 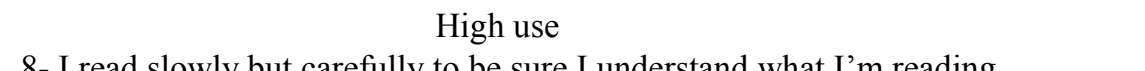 & 351 & 1 & 28 \\
\hline SUP & $\begin{array}{l}\text { 20- I paraphrase (restate ideas in my own words) to better understand what I } \\
\text { read. }\end{array}$ & 3.52 & 1 & 29 \\
\hline PROB & 11- I try to get back on track when I lose concentration. & 3.77 & 1 & 30 \\
\hline
\end{tabular}

Table-1. ranks the reported strategies in terms of overall mean scores. The thirty strategies are arranged in ascending order from the least to the most used. The most used strategies are11 (mean=3.77), 20 (mean=3.52), 8 (mean=3.51) that is, successively, I try to get back on track when I lose concentration; I paraphrase (restate ideas in my own words) to better understand what I read; I read slowly but carefully to be sure I understand what I'm reading. As table states these strategies are problem solving and supportive strategies. Thus, the students are aware of their comprehension process and are able to control and manage when their comprehension breaks down. GLOB strategies 22 (mean=2.6), 7 $($ mean $=2.66)$ and SUP strategies $6($ mean=2.73), 28 $($ mean=2.73) are the least used strategies. This indicates that learners are not able or are not encouraged to use possible techniques.

Therefore, readers employ concentration and simplify text while reading but they do not post- evaluate what they read by summarizing; and do not reflect on and evaluate the text while reading. That is, they prefer to use typographical aids or think about the context in the lowest level.

Without interpretation of quantitative information (raw materials) gathered by questionnaires, we cannot make any decision. So we need a scale to change the numbers into representative and meaningful data. In this regard, the "Key to Average" provided in MARSI (2002) is beneficial. It says whether participants are high, medium or low in any of these strategies.

The reported awareness of strategies is analyzed in Tables 2-7.

\subsection{Global Reading Strategies (GLOB)}

Table 2. Mean for Global Reading Strategies (GLOB)

\begin{tabular}{ccc}
\hline Mean & N & $\%$ \\
\hline H & 17 & 30.37 \\
M & 33 & 58.92 \\
L & 6 & 10.71 \\
\hline
\end{tabular}

The table above shows that 33 (58.92\%) of the participants reported their moderate usage of various GLOB strategies. About 17 (30.37\%) participants out of 56 fall under high usage awareness of reading strategies while only $6(10.71 \%)$ participants show their lack of such techniques. All in all, the table represents that a majority of participants are able to monitor and manage their reading. 


\begin{tabular}{|c|c|c|c|c|c|c|c|}
\hline Strategies & 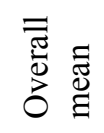 & 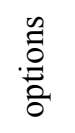 & 1 & 2 & 3 & 4 & 5 \\
\hline \multirow[t]{2}{*}{ 1. I have a purpose in mind when I read. } & 3.23 & $\mathrm{~N}$ & 6 & 12 & 13 & 10 & 15 \\
\hline & & $\%$ & 10.71 & 21.43 & 23.22 & 17.86 & 26.77 \\
\hline \multirow{2}{*}{$\begin{array}{l}\text { 3. I think about what I know to help me understand } \\
\text { what I read. }\end{array}$} & 3.35 & $\mathrm{~N}$ & 4 & 9 & 14 & 19 & 10 \\
\hline & & $\%$ & 7.14 & 16.07 & 25 & 33.93 & 17.86 \\
\hline \multirow{2}{*}{$\begin{array}{l}\text { 4. I preview the text to see what it's about before } \\
\text { reading it. }\end{array}$} & 3.40 & $\mathrm{~N}$ & 4 & 12 & 13 & 12 & 15 \\
\hline & & $\%$ & 7.14 & 21.43 & 23.22 & 21.43 & 26.77 \\
\hline \multirow[t]{2}{*}{$\begin{array}{l}\text { 7. I think about whether the content of the text fits my } \\
\text { reading purpose. }\end{array}$} & 2.66 & $\mathrm{~N}$ & 13 & 16 & 12 & 11 & 5 \\
\hline & & $\%$ & 23.2 & 28.5 & 21.43 & 19.64 & 8.92 \\
\hline \multirow[t]{2}{*}{$\begin{array}{l}\text { 10. I skim the text first by noting characteristics like } \\
\text { length and organization. }\end{array}$} & 3.19 & $\mathrm{~N}$ & 10 & 10 & 11 & 12 & 16 \\
\hline & & $\%$ & 17.86 & 17.86 & 19.64 & 21.43 & 28.57 \\
\hline \multirow[t]{2}{*}{ 14. I decide what to read closely and what to ignore. } & 2.85 & $\mathrm{~N}$ & 14 & 13 & 12 & 12 & 5 \\
\hline & & $\%$ & 25 & 23.22 & 21.43 & 21.43 & 8.92 \\
\hline \multirow{2}{*}{$\begin{array}{l}\text { 17. I use tables, figures, and pictures in text to increase } \\
\text { my understanding. }\end{array}$} & 3.44 & $\mathrm{~N}$ & 8 & 7 & 14 & 13 & 14 \\
\hline & & $\%$ & 14.29 & 12.5 & 25 & 23.22 & 25 \\
\hline \multirow{2}{*}{$\begin{array}{l}\text { 19. I use context clues to help me better understand } \\
\text { what I'm reading. }\end{array}$} & 3.26 & $\mathrm{~N}$ & 2 & 16 & 12 & 14 & 12 \\
\hline & & $\%$ & $3.5^{\circ}$ & 28.57 & 21.43 & 25 & 21.43 \\
\hline \multirow{2}{*}{$\begin{array}{l}\text { 22. I use typographical aids like bold face and italics to } \\
\text { identify key information. }\end{array}$} & 2.60 & $\mathrm{~N}$ & 14 & 15 & 11 & 8 & 8 \\
\hline & & $\%$ & 25 & 26.77 & 19.64 & 14.29 & 14.29 \\
\hline \multirow{2}{*}{$\begin{array}{l}\text { 23. I critically analyze and evaluate the information } \\
\text { presented in the text. }\end{array}$} & 3.32 & $\mathrm{~N}$ & 8 & 14 & 15 & 10 & 9 \\
\hline & & $\%$ & 14.29 & 25 & 26.77 & 17.86 & 16.07 \\
\hline \multirow{2}{*}{$\begin{array}{l}\text { 25. I check my understanding when I come across } \\
\text { conflicting information. }\end{array}$} & 3.26 & $\mathrm{~N}$ & 1 & 12 & 23 & 12 & 8 \\
\hline & & $\%$ & 1.7 & 21.43 & 41.07 & 21.43 & 14.29 \\
\hline \multirow{2}{*}{$\begin{array}{l}\text { 26. I try to guess what the material is about when I } \\
\text { read. }\end{array}$} & 2.98 & $\mathrm{~N}$ & 8 & 12 & 14 & 16 & 6 \\
\hline & & $\%$ & 14.29 & 21.43 & 25 & 28.57 & 10.71 \\
\hline \multirow{2}{*}{$\begin{array}{l}\text { 29. I check to see if my guesses about the text are right } \\
\text { or wrong. }\end{array}$} & & $\mathrm{N}$ & 12 & 15 & 13 & 8 & 8 \\
\hline & & $\%$ & 21.43 & 26.77 & 23.22 & 14.29 & 14.29 \\
\hline
\end{tabular}

Table-3. is representative of choice distribution in GLOB strategies. Among thirteen strategies in GLOB category, strategy 17 is the most and strategy 22 is the least used among others. It means that $25 \%$ of respondents always or almost always use tables, figures, and pictures in text to increase their understanding. So, the readers resort to any clue related to text such as visual aids and their background knowledge to set the stage for reading act. And the frequency of awareness on strategy 22 shows about $14.29 \%$ of participants is highly aware of this strategy.

\subsection{Problem-Solving Reading Strategies (PROB)}

Table 4. Mean for Problem-Solving Reading Strategies (PROB)

\begin{tabular}{ccc}
\hline Mean & N & $\%$ \\
\hline H & 33 & 58.93 \\
M & 19 & 33.93 \\
L & 4 & 7.14 \\
\hline
\end{tabular}

You can see from Table-4. how frequently readers have applied PROB category strategies with eight sub-scales. This category focuses on repair strategies or solving problems with which reader encounter during reading. The respondents indicate a higher level of strategy awareness up to $58.93 \%(\mathrm{~N}=33)$ while using PROB category such as: adjusting one's 
speed of reading when the text become difficult or easy, guessing the meaning of unknown word and rereading the text to improve comprehension and so on. In contrast, only 4 (7.14\%) participants show the least awareness of such strategies in reading ESP texts. Finally, 19(33.93\%) reported medium usage of PROB category strategies.

Table 5. Analyses of Percentage of Problem-Solving Reading Strategies (PROB)

\begin{tabular}{|c|c|c|c|c|c|c|c|}
\hline Strategies & 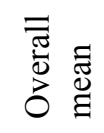 & 总 & 1 & 2 & 3 & 4 & 5 \\
\hline \multirow{2}{*}{$\begin{array}{l}\text { 8. I read slowly but carefully to be sure I } \\
\text { understand what I'm reading. }\end{array}$} & 3.6 & $\mathrm{~N}$ & 5 & 4 & 20 & 17 & 10 \\
\hline & & $\%$ & 8.92 & 7.14 & 35.71 & 30.36 & 17.86 \\
\hline \multirow{2}{*}{$\begin{array}{l}\text { 11. I try to get back on track when I lose } \\
\text { concentration. }\end{array}$} & 3.77 & $\mathrm{~N}$ & 1 & 5 & 17 & 15 & 18 \\
\hline & & $\%$ & 1.79 & 8.92 & 30.36 & 26.77 & 32.14 \\
\hline \multirow{2}{*}{$\begin{array}{l}\text { 13. I adjust my reading speed according } \\
\text { to what I'm reading. }\end{array}$} & 3.2 & $\mathrm{~N}$ & 9 & 11 & 10 & 16 & 10 \\
\hline & & $\%$ & 16.07 & 19.64 & 17.86 & 28.57 & 17.86 \\
\hline \multirow{2}{*}{$\begin{array}{l}\text { 16. When text becomes difficult, I pay } \\
\text { closer attention to what I'm reading. }\end{array}$} & 3.30 & $\mathrm{~N}$ & 3 & 10 & 12 & 13 & 18 \\
\hline & & $\%$ & 5.36 & 17.86 & 21.43 & 23.22 & 32.14 \\
\hline \multirow{2}{*}{$\begin{array}{l}\text { 18. I stop from time to time and think } \\
\text { about what I'm reading. }\end{array}$} & 3.22 & $\mathrm{~N}$ & 4 & 14 & 16 & 10 & 12 \\
\hline & & $\%$ & 7.14 & 25 & 28.57 & 17.86 & 21.43 \\
\hline \multirow{2}{*}{$\begin{array}{l}\text { 21. I try to picture or visualize } \\
\text { information to help remember what I } \\
\text { read. }\end{array}$} & 3.30 & $\mathrm{~N}$ & 6 & 10 & 8 & 17 & 15 \\
\hline & & $\%$ & 10.71 & 17.86 & 14.29 & 30.36 & 26.77 \\
\hline \multirow{2}{*}{$\begin{array}{l}\text { 27. When text becomes difficult, I re-read } \\
\text { to increase my understanding. }\end{array}$} & 3.48 & $\mathrm{~N}$ & 6 & 6 & 13 & 14 & 17 \\
\hline & & $\%$ & 10.71 & 10.71 & 23.22 & 25 & 30.36 \\
\hline \multirow{2}{*}{$\begin{array}{l}\text { 30. I try to guess the meaning of } \\
\text { unknown words or phrases. }\end{array}$} & 3.33 & $\mathrm{~N}$ & 4 & 10 & 11 & 22 & 9 \\
\hline & & $\%$ & 7.14 & 17.86 & 19.64 & 32.29 & 16.07 \\
\hline
\end{tabular}

Table-5., as the representative table of PROB strategies, states among eight strategies in PROB category, strategy 11 enjoys the highest frequency and overall means score. Strategy 13 equally falls on the lowest level of usage. It means that $32.14 \%$ of respondents acknowledged the high awareness of getting back on track when they lose concentration and cope up with problems that impede understanding or result in faulty comprehension. Low frequency of strategy 13$I$ adjust my reading speed according to what I'm reading- indicates reader's low management and monitoring on reading speed. As the rapidity of reading increases the reader's concentration decreases. In contrast, low speed results in fragmented reading and losing cohesive relationships.

\subsection{Support Reading Strategies}

Table 6. Mean for Support Reading Strategies

\begin{tabular}{ccc}
\hline Mean & N & $\%$ \\
\hline H & 18 & 32.14 \\
M & 29 & 51.79 \\
L & 9 & 16.07 \\
\hline
\end{tabular}

Table-6. represents that as it is the case with GLOB strategies, readers prefer moderate usage of SUP category. Respondents up to $51.79 \%$ (29 participants) selected sub-scales of this category. About 32.14\% (18 participants) fall 
under high usage while $16.07 \%$ (9 participants) indicate low mean score. This means that majority of students reported awareness of strategy use that could assist them to understand the text and sustain responsiveness to reading.

Table 7. Analyses of percentage of Support Reading Strategies (SUP)

\begin{tabular}{|c|c|c|c|c|c|c|c|}
\hline Strategies & 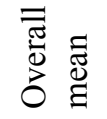 & $\cdot \frac{n}{0}$ & 1 & 2 & 3 & 4 & 5 \\
\hline \multirow{2}{*}{$\begin{array}{l}\text { 2. I take notes while reading to help me } \\
\text { understand what I read. }\end{array}$} & 2.99 & $\mathrm{~N}$ & 10 & 13 & 9 & 14 & 10 \\
\hline & & $\%$ & 17.86 & 23.22 & 16.07 & 25 & 17.86 \\
\hline \multirow{2}{*}{$\begin{array}{l}\text { 5. When text becomes difficult, I read } \\
\text { aloud to help me understand what I read. }\end{array}$} & 3.39 & $\mathrm{~N}$ & 6 & 13 & 10 & 14 & 13 \\
\hline & & $\%$ & 10.71 & 23.22 & 17.86 & 25 & 23.22 \\
\hline \multirow{2}{*}{$\begin{array}{l}\text { 6. I summarize what I read to reflect on } \\
\text { important information in the text. }\end{array}$} & 2.73 & $\mathrm{~N}$ & 13 & 15 & 7 & 13 & 8 \\
\hline & & $\%$ & 23.22 & 26.77 & 12.5 & 23.22 & 14.29 \\
\hline \multirow{2}{*}{$\begin{array}{l}\text { 9. I discuss what I read with others to } \\
\text { check my understanding. }\end{array}$} & 3.4 & $\mathrm{~N}$ & 12 & 10 & 11 & 10 & 13 \\
\hline & & $\%$ & 21.43 & 17.86 & 19.64 & 17.86 & 23.22 \\
\hline \multirow{2}{*}{$\begin{array}{l}\text { 12. I underline or circle information in the } \\
\text { text to help me remember it. }\end{array}$} & 3.48 & $\mathrm{~N}$ & 3 & 12 & 10 & 12 & 19 \\
\hline & & $\%$ & 5.36 & 21.43 & 17.86 & 21.43 & 33.93 \\
\hline \multirow{2}{*}{$\begin{array}{l}\text { 15. I use reference materials such as } \\
\text { dictionaries to help me understand what I } \\
\text { read. }\end{array}$} & 3.35 & $\mathrm{~N}$ & 8 & 14 & 8 & 10 & 16 \\
\hline & & $\%$ & 14.29 & 25 & 14.29 & 17.86 & 28.57 \\
\hline \multirow{2}{*}{$\begin{array}{l}\text { 20. I paraphrase (restate ideas in my own } \\
\text { words) to better understand what I read. }\end{array}$} & 3.52 & $\mathrm{~N}$ & 4 & 8 & 17 & 19 & 8 \\
\hline & & $\%$ & 7.14 & 14.29 & 30.36 & 33.93 & 14.29 \\
\hline \multirow{2}{*}{$\begin{array}{l}\text { 24. I go back and forth in the text to find } \\
\text { relationships among ideas in it. }\end{array}$} & 3.12 & $\mathrm{~N}$ & 6 & 15 & 9 & 18 & 8 \\
\hline & & $\%$ & 10.71 & 26.77 & 16.07 & 32.14 & 14.29 \\
\hline \multirow{2}{*}{$\begin{array}{l}\text { 28. I ask myself questions I like to have } \\
\text { answered in the text. }\end{array}$} & 2.73 & $\mathrm{~N}$ & 15 & 15 & 9 & 11 & 6 \\
\hline & & $\%$ & 26.77 & 26.77 & 16.07 & 19.64 & 10.71 \\
\hline
\end{tabular}

Table-7. gives a clean picture of choice distribution in SUP strategy application. Strategy 20 - I paraphrase (restate ideas in my own words) to better understand what I read-shows that the respondents are very concerned about the needs to understand the text given, and simplify the language to enhance comprehension. Strategy 6, 28 equally fall on the lowest level. At their highest level, strategy 6 happens 14.29\% while strategy 28 happens 10.72\%. Asking intelligent questions and summarizing in native language that involve learners in active thinking and cognitive processes have low status among support mechanisms.

\section{Discussion and Conclusion}

The resulted data and representative tables pave the way for answering the research questions.

First, when the participants were asked to report their strategy employment while reading ESP texts, as the tables of choice distribution show, they selected $1 \leq$ option $1 \leq 15 ; 5 \leq$ option $2 \leq 16 ; 7 \leq$ option $3 \leq 23 ; 8 \leq$ option $4 \leq 22$; $5 \leq$ option $5 \leq 19$ (see tables 3,5,7). This means that selectors of option 1 never, and selectors of option 2 almost never or occasionally use strategies. As the scales show significant numbers of participants are low strategy users. So we can say that they should be accustomed to strategy use and to this end, explicit strategy training parallel with course instruction will be beneficial. Their low strategy use is in part due to their lack of awareness. Therefore the answer to the first research question - Are the learners aware of the conscious strategy use? Is 'NO', some of the participants are not aware of the strategies and do not use them effectively. Second, there were overall significant differences in strategy use among the 56 participants when reading in ESP.

Third, table 1 represents ranking of individual strategies in the ascending order, participants mostly preferred strategies 11 (PROB: I try to get back on track when I lose concentration) and 20 (SUP: I paraphrase (restate ideas in my own words) to better understand what I read.), while they used strategies 22 (GLOB: I use typographical aids like bold face and italics to identify key information), 7 (GLOB: I think about whether the content of the text fits my reading purpose ) and 6 ( GLOB: I summarize what I read to reflect on important information in the text) with the lowest frequency. Therefore, readers mostly employ concentration and simplify text while reading. But they do not post-evaluate their 
comprehension by summarizing; and do not reflect on the text or evaluate it while reading by using typographical aids and thinking about the content to make connection between the new information and previously learned one. As a result, they would be unable to structure and restructure the mental network which is crucial in leaning and entrenching knowledge in long term memory.

Forth, specifically, participants reported more "Problem Solving Strategies", about 58.93\% at its highest level. However, differences between "Global Reading Strategies" (30.37\%) and "Support Reading Strategies" (32.14\%) were not significant (see tables $2,4,6$ ). This is part of the answer to question two. Table 1 gives a clear picture of the least frequently used up to the most frequently used strategies in terms of overall mean scores. In this way we can find out the rest of answer to question two - what are the most frequently used strategies among Iranian ESP learners? At last, table 1 reveals that approximately all of the ESP learners were moderate reading strategy users who preferred for problem solving strategies regardless of their field of study.

Retrospectively, regarding the Related Studies part, it is noticeable that the result of this study is in parallel with the previous findings. It is suggestive that working on raising metacognitive awareness deserves more attention if the purpose is to bring about fruitful changes in instructional outcomes. Besides, although many researches have been done in this field, their implications are rarely brought about into action: it is representative of how research studies and instructional systems work separately. Therefore, in reading comprehension, not only linguistic competence but also are skills and strategies underling performance essential. In this regard learning how to learn and employ strategies is of high importance. In this study, the participants reflected on the ways of dealing with the texts, and reported their manipulation of strategies while reading ESP text. This procedure could be adopted as a fruitful feedback after reading time in the classroom. As well as providing questionnaires, other ways like open-ended questions, talking aloud about the strategies used have their own advantages. The teacher also can provide a mini-discussion opportunity for learners to negotiate why and how they are using strategies.

In reality, the inclusion of foreign languages in school curriculums is not motivated entirely by the desire to foster communication between students; in fact, the immediate goal is to foster intellectual development. But, in ESP courses, students come with specific needs, and insufficient knowledge to take part in the courses which are not long enough to cover their overall needs. Therefore, material writers of ESP may likely pay more attention to learners' sociocultural and educational situations. Researchers may also find ways of dealing with the psychological aspects of strategy management. Furthermore, material writers could integrate reflective activities not only for the purpose of the activities assigned to deal with objectives but also for the purpose of raising learners' consciousness in strategy employment. As a result, the reading process will become more comprehensive and enjoyable.

\section{References}

Abdul Aziz, N. (2011, july). The Reading Sterategies Awareness among English as a Second Language (ESL)Learners in Malaysia's University. (1), 778-784. doi:10.4304/tpls.1.7.778-784.

Brown, D. (2006). Principles of Language Learning and Teaching (5th ed.). New York: Longman.

Dudley-Evans, T., \& St John, M. (1998). Developement in English for Specific Purposes. United Kingdom: Cambridge University Press.

Flynn, N., \& Stainthorp, R. (2006). The learning and Teaching of Reading and Writing. England: Wiley.

Halley, H. M., \& Austin, Y. T. (2004). Content-Based Second Languge Teaching and Learning. Boston: Pearson.

Jafari, M., \& Shokrpoer, R. (2012). The Reading Sterategies Used by Iranian ESP Students to Comrehend Authentic Expository Texts in English. International journal of Applied Linguistics and English Litreture, 1(4), 102-113. doi:10.7575/ijalel.v.1n.4p.102.

Lindsay, C., \& Knight, P. (2010). Learning and teaching English. New York city: Oxford University Press.

Mahdavi, M. (2012). The Role of Metacognitive Sterategy Training in EFL Reading and Vocabulary Developement in an "Input Poor" Enviroment. Chabahar, Iran: Unpublished Theses Paper.

Martinez, A. C. (2008). Analysis of ESP University Students'Reading Sterategy Awareness. Iberica, 165-176.

Mclaughlin, M. (2010). Content area reading teaching and learning in an age of multiple literacies. United States: Pearson.

Mokhtari, K., \& Reichard, C. (2002). Metacognitive Awareness of Reading Strategies Inventory (MARSI) Version 1.0. Journal of Educational Psychology, 49(2), 249-259.

Nunan, D. (2006). Second Language Teaching and Learning. United States: Heinle \& Heinle publishers.

Richards, J. c., \& Renandya, W. A. (2002). Methodology in Language Teaching Teaching an Anthology of Current Practice. United States: Cambridge University Press.

Stok, M. F. (2012, november). Main Idea Comprehension in FL University Students: Problem and Causes. ARTESOLESP E-journal, 2(1), 13-31. 
Tabatabaie, o., \& Assari, F. (2011). Investigating Strategic Processes of L2 Reading Comprehension among Collegiate Iranian ESP Learners across Three Academic Fields of Study. Canadian Research \& Development Center of Sciences and Cultures, pp. 205-214.

Wearmouth, J., Solar, J., \& Reid, G. (2003). Meating Difficulties in Literacy Development. New York: Rout ledgefalmer.

Williams, M., \& Burden, R. L. (2002). Phychology for Language Taechers a Social Constructivist Approach. Cambridge University Press: United Kingdom. 